\title{
Still ignored and still invisible: the situation of displaced people and people affected by disasters in the COVID-19 pandemic
}

\author{
Roberto Ariel Abeldaño Zuñiga' ${ }^{1}$ · Ana María González Villoria ${ }^{1}$
}

Received: 15 February 2021 / Accepted: 29 March 2021 / Published online: 13 April 2021

(c) The Author(s), under exclusive licence to Springer Japan KK, part of Springer Nature 2021

\begin{abstract}
One year after the COVID-19 pandemic was declared around the world, this comment aims to reflect on the current state of vulnerability in which displaced people and people affected by disasters can still find themselves around the world. There is still no accurate data available to assess the magnitude of the phenomena, so these people are still invisible. This contribution aims to dialogue with the previous contributions in the field, as well as to provide up-to-date estimates of people affected by disasters worldwide in 2020, with the purpose of demonstrate the vulnerability of these people during the first year of the COVID-19 pandemic.
\end{abstract}

Keywords COVID-19 - Internal displacements · Disasters

\section{Background}

In July 2020, Orendain and Djalante (2020) published in this Journal a very interesting commentary entitled "Ignored and invisible: internally displaced persons (IDPs) in the face of COVID-19 pandemic". In that contribution, the authors reflected on the differential impacts and high vulnerability that internally displaced people must face during the COVID-19 pandemic. The authors also provided estimates of internally displaced persons in 2019.

With the data available from 3 previous years (2017-2019), the authors pointed out that in 2017 there were 30.6 million global displacements due to disasters and conflicts, 27.8 million in 2018 and 33.4 million in 2019. These tens of millions of displacements have affected mainly people from Southeast Asian countries and the African continent, as the authors stated in their contribution (Orendain and Djalante 2020).

On the other hand, during 2020, according to the Center for Research on the Epidemiology of Disasters (CRED) from

Handled by Osamu Saito, Institute for Global Environmental Strategies, Japan.

Roberto Ariel Abeldaño Zuñiga

ariabeldanho@gmail.com

1 University of Sierra Sur, Guillermo Rojas Mijangos SN, Miahuatlán de Porfirio Diaz, 70800 Oaxaca, Mexico
Belgium, 482 disasters were registered around the world, affecting 95,385,713 people (Université Catholique de Louvain 2021).

This contribution aims to dialogue with the previous contributions from Orendain and Djalante, as well as to provide up-to-date estimates of people affected by disasters worldwide in 2020, with the purpose of demonstrating the vulnerability of these people during the first year of the COVID-19 pandemic.

\section{Affected people by displacements and disasters in numbers}

Concerning this comment, we want to specify three aspects that may be from different nature, but that ultimately have the same consequence for the affected people: internally displaced persons, people affected by disasters and caravans of international migrants.

First, at the beginning of 2021, we can establish that, according to data from the Internal Displacements Monitoring Centre mid-year update (2020) published last September, the number of new internally displaced persons during the first semester of 2020 was 14.6 million, due to conflicts and disasters, in 127 countries and territories. This represents almost 4 million more than that registered in the first semester of 2019 (10.8 million). Although at the end of February 2021, we still do not have the final data for the 
entire year 2020. This is still concerning, because it means that no government has an accurate and up-to-date estimate of internally displaced persons to provide the humanitarian assistance that people need during the COVID-19 pandemic, as Orendain and Djalante (2020) pointed out more than six months ago.

Second, we want to highlight people affected by disasters in this comment because another data source, EMDAT (Université Catholique de Louvain 2021), has published its data for the year 2020. This report has estimated 1,001,924 people who lost their homes and a total of $95,385,713$ people affected by disasters worldwide. The events that affected the most people in 2020 were Cyclone Amphan in Southeast Asia, Typhoon Ulysses (Vamco) in the Philippines, Hurricane Eta in Central America and other events in Africa (Table 1).

On the other hand, during the first two months of 2021, EM-DAT has registered 48 disasters that have affected a total of 863,958 people worldwide (Université Catholique de Louvain 2021). The countries most affected during the first months of 2021 are Mozambique, Indonesia, the Syrian Arab Republic, Fiji, the Philippines and Malaysia. The most affected countries during January 2020 and February 2021, were from the regions of East Asia and the African continent, as stated in the previous paragraphs.

The Philippines is another important case to highlight. The year 2020 has hit the Philippines like never. As of the pandemic, a total lockdown was imposed from March to June, which was later modified at the community level, with the dynamics of the pandemic. In 2020, the Taal volcano erupted, a magnitude 6.6 earthquake, 20 tropical cyclones and typhoon Molave (Quinta), super typhoon Goni (Rolly) and typhoon Vamco (Ulyssess) stand out. These three typhoons affected 7,864,405 people (Université Catholique de Louvain 2021). The COVID-19 pandemic has made recovery and recovery even more difficult for people affected by disasters and has synergized with these events.

With these data available, we can affirm that tens of millions of people were highly exposed to a potential
SARS-CoV-2 infection due to internal displacements or by a major disaster during the past year. Paradoxically, the objective of governments in the current months is that people can stay at home to maintain health and save their lives, according to the World Health Organization recommendations (World Health Organization 2020). However, tens of millions of people worldwide, and mainly in less developed countries, were threatened by conflicts, disasters, or other environmental risks. For this reason, they had to leave -leaving their homes- to achieve that same goal: "survinving". For these people, who already face the devastating consequences and effects of their forced displacement daily, the arrival of the COVID-19 pandemic brings a series of new challenges, like accessibility to the health system and its new barriers. On the other hand, they face crowding situations if they are in a refugee shelters or homeless. Likewise, their vulnerability is increased by the economic debacle that the pandemic has caused in many countries, which, added to a disaster situation of great magnitude, may increase that vulnerability, as Orendain and Djalante (2020) had noticed.

The third point we want to highlight is related to the caravans of international migrants in Central America. This is another side of the same problem; migrants who left some Central American countries in the direction of Mexico at the beginning of 2021 with the purpose of reaching the USA (Daily Mail 2021) are highly exposed in Mexico. As of march 4th 2021, in Mexico, there were more than 2 million cases and more than 180,000 deaths, being the third country with the most deaths from COVID-19 worldwide (Our World in Data 2021). Displaced populations have urgent care needs and are exposed to recurrent or long-term displacement (as in the case of people from Central America) so that the invisibility of their situation increases their level of risk and lack of protection against the pandemic.

In this regard, OECD has identified several specific factors that put immigrants at greater exposure and risk of transmission of COVID-19. Immigrants in an irregular situation, for example, may be less willing to go to an examination or to hospitals. Temporary migrants are not covered by
Table 1 The 2020 top ten disasters, by total affected people, disaster type and countries. EM-DAT database

\begin{tabular}{llllc}
\hline Disaster type & Event name & Country & Region & Total affected people \\
\hline Storm & Cyclone Amphan & India & Southern Asia & $18,000,000$ \\
Flood & & China & Eastern Asia & $10,000,000$ \\
Flood & & Bangladesh & Southern Asia & $7,600,000$ \\
Drought & & Mali & Western Africa & 6800,000 \\
Storm & Typhoon Ulysses (Vamco) & The Philippines & South-Eastern Asia & $4,945,461$ \\
Storm & Hurricane Eta & Honduras & Central America & $4,566,584$ \\
Flood & & China & Eastern Asia & $4,200,000$ \\
Drought & & The Niger & Western Africa & $3,700,000$ \\
Drought & & Burkina Faso & Western Africa & $2,900,000$ \\
Storm & Cyclone Amphan & Bangladesh & Southern Asia & $2,600,000$ \\
\hline
\end{tabular}


social security systems, including health, are less likely to do remote work and are more exposed to street work than residents. On the other hand, quantifying the impact of COVID-19 in the immigrant population is also a challenge, since national health systems record basic statistics on the number and characteristics of COVID-19 cases, based on the official statistics, tests and hospitalizations (Organisation for Economic \& Co-operation and Development 2020).

\section{Actions taken in some countries}

Since the declaration of the COVID-19 pandemic, some international organizations, such as the Internal Displacements Monitoring Centre, which maintains a permanent record of the global displacement situation, began to issue alerts for people displaced by violence or conflict (Internal Displacements Monitoring Centre 2021).

The IDMC has published some reports and expert opinions regarding the internal displacement situation during the pandemic. In the 2020 mid-year update (Internal Displacements Monitoring Centre 2020), there have been estimated 3.6 million displaced in Yemen. In addition, 2362 COVID19 infections and 643 deaths have been confirmed in this country (Our World in Data 2021) until March 4th. However, it is highly likely that these numbers are underestimated due to the low testing capacity and the current conflict situation in Yemen. An IDMC survey has reported that $45 \%$ of internally displaced people have reported symptoms consistent with COVID-19, as compared to $30 \%$ of non-displaced people (Yasukawa 2021). This could be motivated by displacement conditions, lack of water, hygiene and overcrowding. This type of survey has been useful to produce estimates of the impact of the pandemic on the number of potential infected and to analyze barriers to access to treatment in positive cases.

Another report from the IDMC has stated that the Covid19 pandemic has increased the vulnerability of displaced populations, and, consequently, the severity of the displacement situation has increased in many Asian and African countries. This has also triggered some actions by human organizations, since due to the deterioration of security conditions in many countries, humanitarian agents intensified their efforts to document the living conditions of internally displaced persons (Sydney 2021).

It is a fact that governments, emergency responders and humanitarian organizations responding to displacement caused by disasters during the COVID-19 pandemic face a multiple challenge that includes safe evacuation, maintenance of social distancing measures, hygiene safe and prevention of massive infections. For these challenges, the IDMC has issued a series of recommendations when cyclone Amphan hit India, where 818,000 people had to be evacuated preventively, to later reach 2.4 million evacuees. In these cases, the IDMC has recommended increasing the number of emergency shelters to avoid overcrowding, testing for COVID-19 on arrival and departure, providing isolation and treatment rooms for positive cases, providing evacuations with essential and sanitized supplies, use hotels, schools, religious buildings and other existing infrastructure for additional shelters (Kurkaa 2020). However, it is evident that not all countries or regions have sufficient resources and infrastructure to implement these recommendations in the field.

In the US, the Federal Emergency Management Agency and RED Cross, have published practical guidelines focusing in the 2020 hurricane season, during the COVID-19 context (American Red Cross 2020; FEMA 2020). The Lancet Migration has launched an Statement including public health and policy recommendations and perspectives to ensure migrants and refugees: have access to healthcare; are included in prevention, preparedness and response; and are part of responsible and transparent public information strategies, during the COVID-19 pandemic (Lancet Migration 2020).

\section{[In]Conclusions}

Seven months after the comment was published, these people continue to be invisible, to the point that we do not have an accurate estimate of the magnitude of displaced people throughout 2020. The pandemic has dominated the international political agenda, the international media and all public opinion. This contributed to the fact that this situation of vulnerability of displaced people and people affected by disaster situations remains invisible. In this sense, it is crucial to make visible the situations that occur in this context.

The conditions surrounding these processes, such as barriers to health services, poverty, working conditions and exploitation in the case of internally displaced and migrant people, can pose risks to the health of migrants. The conditions turn into a state of vulnerability due to the stress of the trip, which can be associated with an increase in infectious diseases, especially in the respiratory and intestinal tracts (Castelli and Sulis 2017). The overcrowded conditions in the migration stations, lack of food and now COVID-19 is one more mitigating factor that puts the lives of migrants at risk. Although some countries, such as in the case of Colombia, indicate that they have guidelines for the care of migrants after the pandemic, it is necessary to see how this can be implemented in practice (International Organization of Migration 2020). Governments must adopt an inclusive approach to ensure that all affected people, internally displaced and migrants, consider public health planning, response and messages. If we think about the three basic 
prevention premises that have been declared since the beginning of the pandemic: "stay at home," "wash your hands," and "maintain social distance," in none of the cases mentioned, these people can carry them out all time. Hence, their vulnerability is still increased.

Likewise, it has been described that the COVID-19 pandemic and disasters during 2020 have synergized to affect biodiversity, contributing to the existing conditions of poverty and social and health vulnerability (Rondeau et al. 2020); as well as various dimensions of health have been affected by the pandemic and disasters, for example, mental health (Cosic et al. 2020). These dimensions remain unattended in displaced people or affected by disasters.

\section{References}

American Red Cross (2020) Preparing FOR Disaster during COVID19 | American Red Cross. https://www.redcross.org/get-help/ how-to-prepare-for-emergencies/types-of-emergencies/coronavirus-safety/preparing-for-disaster-during-covid-19.html. Accessed 4 Mar 2021.

Castelli F, Sulis G (2017) Migration and infectious diseases. ClinMicrobiol Infect 23(5):283-289. https://doi.org/10.1016/j.cmi.2017. 03.012

Cosic K, Popovic S, Sarlija M, Kesedzic I (2020) Impact of human disasters and COVID-19 pandemic on mental health: potential of digital psychiatry. Psychiatr Danub 32(1):25-31. https://doi.org/ $10.24869 /$ psyd.2020.25

Daily Mail (2021) Second migrant caravan to leave Honduras after Guatemala stopped first caravan of 2021. https://www.dailymail. co.uk/news/article-9172799/Second-migrant-caravan-leaveHonduras-Guatemala-stopped-caravan-2021.html. Accessed 4 Mar 2021

FEMA (2020) COVID-19 Pandemic Operational Guidance for the 2020 Hurricane Season I FEMA.gov. https://www.fema.gov/media-colle ction/covid-19-pandemic-operational-guidance-2020-hurricaneseason. Accessed 4 Mar 2021

Internal Displacements Monitoring Centre (2020) Internal displacement 2020: Mid-Year Update I IDMC. https://www.internal-displ acement.org/publications/internal-displacement-2020-mid-yearupdate. Accessed 4 Mar 2021

Internal Displacements Monitoring Centre (2021) Internal Displacements Monitoring Centre. https://www.internal-displacement. org/. Accessed 4 Mar 2021

International Organization of Migration (2020) Programa Migración \& Salud (Issue 03). https://repositoryoim.org/bitstream/handle/
20.500.11788/2303/Boletin_OIM-Salud_Respuesta_COVID19_ Junio2020.pdf?sequence $=1$ \&isAllowed=y. Accessed 4 Mar 2021

Kurkaa M (2020) Lessons learned: responding to disaster displacement in the time of COVID-19. Internal Displacements Monitoring Centre. https://www.internal-displacement.org/expert-opini on/lessons-learned-responding-to-disaster-displacement-in-thetime-of-covid-19. Accessed 4 Mar 2021.

Lancet Migration (2020) Leaving no one behind in the Covid-19 Pandemic: a call for urgent global action to include migrants \& refugees in the COVID-19 response: Vol. April (Issue 20). https:// 1 bec58c3-8dcb-46b0-bb2a-fd4addf0b29a.filesusr.com/ugd/ 188e74_b87afbfe45e44eecb13a45a5cea61209.pdf. Accessed 4 Mar 2021

Orendain DJA, Djalante R (2020) Ignored and invisible: internally displaced persons (IDPs) in the face of COVID-19 pandemic. Sustain Sci 16(1):337-340. https://doi.org/10.1007/s11625-020-00848-0

Organisation for Economic, \& Co-operation and Development (2020) What is the impact of the COVID-19 pandemic on immigrants and their children? (Issue October). https://www.oecd.org/coronavirus/policy-responses/what-is-the-impact-of-the-covid-19-pande mic-on-immigrants-and-their-children-e7cbb7de/. Accessed 4 Mar 2021

Our World in Data (2021) Coronavirus pandemic (COVID-19)statistics and research. https://ourworldindata.org/coronavirus. Accessed 4 Mar 2021.

Rondeau D, Perry B, Grimard F (2020) The consequences of COVID-19 and other disasters for wildlife and biodiversity. Environ Resour Econ 76(4):945-961. https://doi.org/10.1007/ s10640-020-00480-7

Sydney C (2021) Displacement severity on the rise after a challenging year. Internal Displacements Monitoring Centre. https://www. internal-displacement.org/expert-opinion/displacement-severityon-the-rise-after-a-challenging-year. Accessed 4 Mar 2021

Université Catholique de Louvain (2021) EM-DAT । The international disasters database. https://www.emdat.be/. Accessed 4 Mar 2021

World Health Organization (2020) Coronavirus disease (COVID-19). https://www.who.int/emergencies/diseases/novel-coronavirus2019. Accessed 4 Mar 2021

Yasukawa L (2021) New survey shows how COVID-19 exacerbates the critical needs of Yemens's IDPS. Internal Displacements Monitoring Centre. https://www.internal-displacement.org/expert-opinion/ new-survey-shows-how-covid-19-exacerbates-the-critical-needsof-yemens-idps. Accessed 4 Mar 2021

Publisher's Note Springer Nature remains neutral with regard to jurisdictional claims in published maps and institutional affiliations. 